\title{
Arte e História do Ser: algumas considerações sobre o caminho do pensamento de Heidegger a partir do ensaio $A$ origem da Obra de arte
}

\section{Art and History of Being: some considerations on the path of Heidegger's thought from the essay The Origin of the Work of Art}

\author{
Prof $^{a}$. Dra ${ }^{\mathrm{a}}$. Luciana da Costa Dias \\ lucianacdias@yahoo.com.br \\ Universidade Federal de Ouro Preto
}

Pretende-se discutir a relação entre a questão da arte e a história do ser, tal como esta progressivamente se constrói na obra de Martin Heidegger, sobretudo a partir de meados da década de 1930, de modo a identificar e destacar o papel fundamental que a abordagem desta questão detém para a chamada viragem (Kehre) e o caminho do seu pensamento para além dos limites da analítica existencial, empreendida em Ser e Tempo (1927) e em direção à construção da chamada "história do ser" e à questão do acabamento da metafísica como niilismo, desenvolvida na última fase de sua obra.

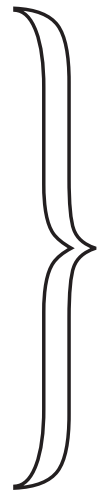

PALAVRAS-CHAVE Ontologia ; História do Ser ; Estética ; Heidegger ; Martin

We intend to discuss the relationship between art and the history of being, as this is gradually build on the work of Martin Heidegger, particularly from the mid-1930s, in order to identify and highlight the key role that this issue has for the so-called turning (Kehre) at his work and the path of his thinking, beyond the limits of existential analysis, undertaken in Being and Time (1927) and towards the construction of a "history of being" and the finishing of metaphysic as nihilism, developed in the last phase of heideggerian work.

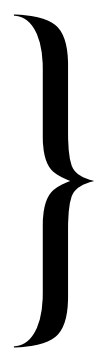

KEYWORDS Ontology ; History of Being ; Aesthetics ; Heidegger, Martin 
Não deixa de ser curioso notar que arte e poesia, elementos que serão, posteriormente, centrais na obra de Heidegger, mal são mencionados em Ser e Tempo. Há apenas uma breve menção no $\S 48$, menção esta que de modo algum parece dar conta (ou pretender dar conta) do fenômeno da arte. Ao diferenciar o que caracteriza o findar específico do ser-aí, Heidegger contrapõe este ao "acabamento de um ser simplesmente dado (eines Vorhandenen)", que parece poder ser um ente qualquer, ao dizer "com a última pincelada está pronto o quadro. ("Gemälde" - quadro ou pintura)". É a referência mais próxima a uma obra de arte que Heidegger faz em Ser e Tempo - e ainda assim, a questão não é realmente abordada. Contudo, esta menção indica que ele parece articular diretamente o quadro com o modo de ser de um ente simplesmente dado, numa perspectiva que parece ser reducionista do fenômeno da arte, sobretudo se comparado ao modo como ele mesmo irá depois caracterizar a questão em $A$ origem da obra de arte. A arte simplesmente parece não ter lugar, na ontologia de Ser e Tempo. Cabe, contudo perguntar: como, e por que isso ocorre? - Sobretudo se tivermos em vista que a abordagem desta questão será fundamental para os rumos posteriores de sua obra, esta pergunta se torna muito pertinente. Afinal, a maioria dos estudos gerais acerca de Heidegger destaca, de algum modo, a importância de seus textos sobre poesia para a compreensão dos aspectos fundamentais de seu pensamento, sobretudo dos textos posteriores a meados da década de 1930.

$\mathrm{E}$, realmente, à primeira vista, parece não haver conexões diretas entre ontologia, história e a "compreensão filosófica" da obra de arte, embora a arte constitua, desde finais do século XVIII, um domínio específico de produção e reflexão, o "domínio estético", consolidado, sobretudo com Hegel a partir de sua defesa da possibilidade de se fazer da estética um campo da filosofia. Contudo, o modo como Heidegger irá conduzir sua discussão acerca da arte em $A$ origem da obra de arte primará por sua tentativa de abordagem direta do fenômeno - a própria obra -, pretendendo iniciar a questão "sobre novas bases" e parecendo desconsiderar o modo como a questão tradicionalmente veio a ser posta pela estética.

Contudo, nos detendo primeiramente em Ser e Tempo, a abertura do mundo é lá o horizonte fático de manifestação de cada ente, sem o qual nenhum outro comportamento intencional pode se dar. A compreensão dos modos de ser dos entes dependem da configuração da abertura. Nesta obra, mundo é visto como pluralidade de significados articulados e sedimentados, o que permite a compreensão do que cada ente em particular é, sendo que o ser-aí não pode se referir ao ente sem a prévia abertura do mundo na qual se Neste contexto, Heidegger (1976) descreve, em Ser e Tempo, como sendo dois os modos pelos quais o ser-aí pode se relacionar com os entes: Zuhandenheit e Vorhandenheit ( $\$ 18 \mathrm{e}$ 
seguintes). São estas as duas formas de configuração da abertura de mundo pelo ser-aí. Esclarecendo estes de forma sucinta, temos que o primeiro destes modos é o da ocupação e o do uso, que se configuraria como o modo imediato do homem em sua lida com os entes, a "dimensão cotidiana" da abertura em que o ser-aí se movimenta. Este é o modo de ser da Zuhandenheit, que é o modo dos entes disponíveis "para a mão" (literalmente: junção dos termos zu, "para", e Hand "mão"), isto é: os entes tomados apenas a partir de seu caráter utensiliar. De início e na maioria das vezes, os entes aparecem ao ser-aí como pragmatas, como coisas com que o homem lida em sua ocupação no mundo (§15).

Os utensílios enquanto utensílios são, portanto, sempre uma coisa "para alguma coisa" que, a bem da verdade, por extensão, acaba sempre também por remeter ainda a outro utensílio, em uma totalidade referencial: o martelo remete aos pregos que remetem à tábua, que remete ao telhado, compondo a totalidade conformativa $^{1}$ em virtude da qual, em última instância, os utensílios se referem sempre ao ser do Dasein e às suas possibilidades enquanto ser-no-mundo, pois dessas possibilidades é que eles recebem suas possibilidades de utilização (HEIDEGGER, 1976, §16).

Já o modo da Vorhandenheit, tal como descrito em ST, o modo de ser dos entes-simplesmente-dados (Vorhandenheit), e diz respeito, em primeira instância, à tentativa de se tomar o ente "em si mesmo", em uma neutralidade artificial, tirando-o destas redes de referência presentes no modo de ser da ocupação. Heidegger entende assim as coisas objetivadas, no modo habitual de a filosofia e de a ciência tratarem os entes (isolando-os, pondo os como um objeto com o qual um sujeito se defronta).

Neste escopo, cabe observar aqui que Vorhandenheit é um termo de tradução complexa do alemão para o português. Diz respeito ao modo de ser dos entes como Vorhandensein, que é o ente tomado como "ente simplesmente dado", "simples-presença", "ente à vista" ou ainda "ente por si subsistente", em algumas das traduções possíveis. É o ente "diante" ("vor") da mão.

A passagem da Zuhandenheit para a Vorhandenheit seria a passagem para uma segunda dimensão da abertura, a partir da qual os entes podem se mostrar. Literalmente. Cabe atentar para os termos em alemão: é a passagem de "ente para (zu) a mão (Hand)" para "ente diante (vor) da mão (Hand)", o que espelha a quebra da utilidade do ente. A dimensão do Vorhandenheit seria derivada da

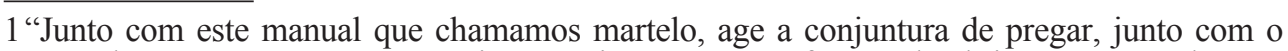
pregar dá-se a proteção contra as intempéries; esta é em função de abrigar o ser-aí, de uma possibilidade de seu ser" (HEIDEGGER, 1976, §18, p. 84). 
tentativa teórica de se perceber especificamente aquilo que antes se mostrara utensiliarmente. Contudo, neste contexto, a passagem de um modo de abertura ao outro, da Zuhandenheit para o modo teórico da Vorhandenheit dependeria, fundamentalmente, do Dasein, e de seu comportamento intencional, que fundaria sempre a abertura do mundo em Ser e Tempo. Ou seja: nesta obra, tanto a Vorhandenheit quanto a Zuhandenheit, os dois modos dos entes se darem no mundo, encontram a origem de sua possibilidade no ser-aí.

Seguindo em nossa análise, temos que estes dois modos, elementos-chave em Ser e Tempo, de maneira nenhuma são facilmente aplicáveis ao ente que se mostra como obra de arte. A arte parecerá escapar totalmente aos termos formulados por Heidegger até então em sua ontologia fundamental. E afirmar isso não é nenhuma novidade, ainda que procuremos aqui em nossa comunicação alcançar que isso foi mais revolucionário, dentro do contexto da obra de Heidegger, do que habitualmente se imagina.

Se em Ser e Tempo o ser das coisas intra-mundanas (isto é: que vêm ao encontro junto com o mundo) fora explicitado a partir dos modos da utensiliaridade (Zuhandenheit) e dos entes-por-si-subsistentes (Vorhandenheit), em $A$ Origem da Obra de Arte percebe-se de modo definitivo que estas concepções se mostram insuficientes.

Poderiam os entes que as obras de arte são serem compreendidos por meio do modo de ser de um utensílio, como um utensílio cujo uso talvez fosse o da fruição estética ou o da decoração? Ou será a arte uma mera coisa à vista, o "objeto neutro", que visamos tomar desprovido de uma rede de utilidade, como algo simplesmente presente à nossa atenção? Um objeto ("objeto estético", talvez?) com o qual nos defrontamos? Com este tipo de questionamento, o que se percebe, na verdade, é que nada parece encaixar bem ou dar conta do fenômeno que a arte representa em sua totalidade. Não há lugar para obras de arte em Ser e Tempo. A obra de arte não cabe em nenhuma dessas duas dimensões da abertura lá caracterizadas sem que algo pareça "faltar". E, de fato, como observamos antes, as obras de arte mal são mencionadas ao longo das mais de 100 páginas que compõe o livro.

O que nos parece é que Heidegger ampliará de forma definitiva o "campo das relações" do homem com os entes, indo assim muito além de Ser e Tempo - não negando o campo lá aberto, mas ampliando este sobre novas bases e possibilidades e, sobretudo, modificando radicalmente o caráter da abertura do mundo. O foco no qual Ser e Tempo se concentra é o foco dos comportamentos existenciais do ser-aí. Após Ser e Tempo, a ênfase saiu cada vez mais do ser-aí em seu "caráter descobridor" (§44) e se encaminhou paulatinamente para o foco 
do próprio ser em seu dar-se (Sobre a essência da verdade, 1943), que deixa de depender do ser-aí singular e de seu comportamento para acontecer (ereignet). É por isso que, a fim de investigar o ser dos entes (como por exemplo, no próprio ensaio $A$ origem da obra de arte), Heidegger não mais centra sua análise no comportamento do Dasein, antes passando a investigar o próprio processo de essencialização do ser para o homem, com o qual a história acontece.

Esta reviravolta na ontologia fundamental começara poucos anos antes, logo em seguida a Ser e Tempo (1927), com os textos Introdução à filosofia (1928/1929) e Conceitos Fundamentais da Metafisica (1930), pois se no primeiro texto Heidegger retoma a problemática do Zuhandenheit e do Vorhandenheit já com um acento maior na questão da verdade, no segundo já irá tematizar a physis em seu puro emergir, elemento que não pode ser entendido como pura e simplesmente Vorhandenheit. Neste sentido, gostaríamos ainda de frisar, se mostra claramente que não se pode falar em uma cisão radical entre os chamados "primeiro" e "último" Heidegger: antes há uma continuidade progressiva de transformação em seu pensamento, até chegarmos ao texto $A$ Origem da Obra de Arte.

Como esclarece Duque Estrada (1999, p. 72),

Embora a estrutura pareça ser a mesma, o argumento que se desenvolverá [em a $\mathrm{AO}$ ] já não é o mesmo daquele desenvolvido em Ser e Tempo. Se em Ser e Tempo o comportamento utilitarista [do Dasein] cumpria uma função esclarecedora tanto do modo de ser do utensílio quanto do modo de ser do objeto, agora, ao contrário, ele se mostra como fator de limitação de nosso encontro com as coisas à perspectiva da utilidade.

Aliás, de maneira alguma pode a obra de arte ser entendida a partir da utensiliaridade. Pode-se mesmo dizer que Heidegger pretende, em A Origem da Obra de Arte, demonstrar que a obra de arte não é um objeto cuja "função" seja a fruição estética - como o pretendem algumas das teorias estéticas da modernidade. Não é a sensação de prazer ou desprazer que está em jogo na caracterização do ser da obra de arte, e esta não é por Heidegger nem mesmo considerada.

A obra de arte, ao contrário dos utensílios, apresenta independência ante a rede de relações exterior, posto não ser algo explicável somente em função de 
suas relações de aplicabilidade, muito menos algo necessitante de contextos para ser entendida (mesmo quem não esteja familiarizado com o Renascimento e seu mundo histórico é capaz de se deter no interior da Capela Sistina e ser tocado por aquilo que se abre diante de seus olhos, por exemplo. Já para se usar uma caneta como o utensílio de escrita que esta é, ao contrário, necessita de toda uma familiaridade com o mundo no qual esse ente encontra sua função e contexto). A obra de arte distingue-se essencialmente de um utensílio, mas nem por isso pode ser confundida com uma mera coisa, como uma simples pedra.

O utensílio (das Zeug), por exemplo, o utensílio sapato, enquanto feito, repousa também em si, como a mera coisa, mas não tem o caráter espontâneo de um bloco de granito. Por outro lado, o utensílio apresenta também uma afinidade com a obra de arte, na medida em que é algo produzido pela mão do homem. Porém, a obra de arte, pelo seu estar-presente auto-suficiente, assemelha-se antes à mera coisa, que é espontânea a nada impelida Todavia, não incluímos as obras de arte entre as meras coisas (HEIDEGGER, UK, 1977, p. 13).

Embora a obra de arte compartilhe sua "origem fabricada" (por ser sempre produto de uma Téchne) com os utensílios, vimos que a obra de arte não se dá do mesmo modo que estes, pois estes, na maioria das vezes, passam despercebidos devido à dinâmica envolvida no próprio uso. A obra de arte como tal, ao contrário, tem o poder de evidenciar a si mesma, se destacando.

Em A origem da obra de arte, Heidegger configura a arte como o "pôr-se em obra da verdade", a própria produção (poiesis) da verdade do ser. Este pôr-se em obra, destacamos, se daria em um duplo movimento ao longo do texto, acentuado pelos dois exemplos de que Heidegger lá se utiliza para explicitação de sua compreensão do que é a obra de arte: a pintura de Van Gogh dos sapatos de um camponês e um Templo Grego. Através da descrição fenomenológica da pintura de Van Gogh, ele alcança, por um lado, o fato de a arte ser o acontecer da verdade do ente, pois esta pode possibilitar a descoberta dos entes em caráter originário, trazendo visibilidade para estes diretamente na abertura do ser - coisa que a perspectiva da utensiliaridade, tal como descrita em Ser e Tempo, não permitiria. Já através da descrição do exemplo do templo grego, alcança Heidegger o fato de a arte ser também a própria abertura do ser no combate entre as instâncias 
que ele denomina como mundo e terra (desvelamento e velamento, significado e mistério). Este segundo movimento do texto heideggeriano acabou, ainda, por se mostrar como o aspecto mais importante, por ser, inclusive, o que possibilita o primeiro movimento mencionado (o de, através da arte, os entes singulares ganharem expressão, como os entes que são, em sua facticidade específica).

O mais importante é que a arte, por ser entendida como poiesis, termo grego que Heidegger traduz como "produção do ser", pode se constituir como acontecimento essencial do ser. É, portanto, a possibilidade de uma nova dimensão da abertura, na qual a própria abertura se viabiliza como abertura e o combate da constituição ontológica se essencializa, podendo vir a ser fixado como tal em uma configuração específica (as obras de arte individuais), que vemos a importância de suas considerações sobre a arte se mostrar, quando pensamos esta na perspectiva do caminho que sua obra seguirá. Ao tematizar a abertura desta nova forma, muito mais profunda que os limites da ontologia fundamental permitira, Heidegger vai com isso (com essa nova dimensão originária da abertura do ser), muito além de ST. Que parecia limitar o dar-se do ser a um comportamento do ser-aí.

Ou seja: em A Origem da Obra de Arte, a abertura do ser é tematizada em sua possibilidade de instauração por meio da obra de arte, o que já a amplia radicalmente com relação a Ser e Tempo. Neste ensaio, Heidegger irá caracterizar as obras de arte como capazes de manifestarem em si uma dimensão própria da abertura, trazendo em si o que Heidegger denomina como sendo o combate da constituição ontológica dos entes, combate este que estaria por trás da instauração da abertura, de toda possibilidade de desvelamento do ser e de verdade originária. Tais considerações teriam sido impensáveis no contexto da ontologia fundamental, tal como construída em Ser e Tempo, a partir da temporalidade extática de um ser-aí singular como ponto central e de base de toda possibilidade ontológica.

Finalizando, colocamos aqui que a mudança pela qual o modo como a abertura em seu acontecer se aprofundou foi um dos elementos determinantes da Kehre (viragem) em sua obra. Heidegger irá reformular a analítica existencial para que haja lugar para a obra de arte na ontologia, com isso reconfigurando totalmente a concepção de Abertura e de ser-aí. E mais do que isso: as obras de arte ganharão um lugar/status ontológico privilegiado para a possibilidade de acontecimento do ser.

A obra de arte passa a ter, assim, um estatuto ontológico bem próprio, se não único. E mais do que isso: ela mantém a abertura como abertura, o combate entre desvelamento e retração se fixaria nas obras de arte na "fissura" $($ Ri $\beta)$ de 
sua forma (Gestalt), no caso, como uma "tensão" que nunca se resolve, e que antes daria às obras de arte sua dinâmica própria. É por trazer em si este combate que Heidegger aproximou as obras de arte em sua essência da physis, que em sua origem se ligaria fundamentalmente à alétheia: a physis como o próprio emergir daquilo que se desvela na alétheia. Toda obra de arte seria em si mesma poiesis, por ser a produção que possibilita a própria eclosão do ser como verdade, "fixando" a verdade na forma.

Deste modo, toda obra de arte é sempre histórica: é o ponto de culminância e a concreção daquilo que está em jogo em sua época, expressão do modo como cada "mundo" sedimentado irá, coletivamente, se determinar essencialmente. O combate entre velamento e desvelamento, que cada obra fixa na forma abre um mundo histórico específico, mas sem jamais esgotá-lo.

Segundo André Duarte (2008, p. 23),

De fato, foi (...) ao longo dos anos trinta que se iniciou o longo processo reflexivo que levou à viragem (Kehre) em seu pensamento, com o consequente abandono do projeto da ontologia fundamental e, portanto, da concepção da história enquanto estrutura ontológica derivada da temporalidade originária do ser do Dasein, em favor da concepção da história do Ocidente como história epocal do ser. A partir de meados dos anos trinta, Heidegger já não se contentava mais em encontrar no Dasein a raiz ontológica da possibilidade dos acontecimentos históricos, pois queria pensar a própria possibilidade da mudança histórica, da transformação do presente, abrindo-o para a um novo começo.

Com isso, se destaca que o que mudará nos textos posteriores a Ser e Tempo é, sobretudo, o modo como Heidegger entende mundo e como este pode se fundar (CASANOVA, 2009). De fato, observamos que "mundo" é um elemento que se ampliará, ganhando novas nuances e, com isso, a própria ontologia fundamental será reformulada. O cerne para se entender esta reformulação será o surgimento da noção de Ereignis, como diversos comentadores, dentre eles Günther Figal (1992) e John Sallis (1990), apontam. Contudo, se por um lado este termo responderá posteriormente como pode ser fundada historicamente a determinação do ser do ente na sua totalidade, no chamado "último Heideg- 

ensaio A origem da Obra de arte

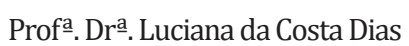

Universidade Federal de Ouro Preto

ger", por outro lado, não conseguimos desvencilhar desta modificação o peso e o caráter determinante que a introdução da abordagem da questão da arte e da poesia trouxe para a ontologia fundamental ao longo dos anos 1930, de modo a conduzir a esta reformulação.

Para entendermos a nova "hermenêutica historial do ser" que surge em sua obra, precisamos ver em que contexto esta surge e, também, discutir e entender estes "novos conceitos" que, progressivamente, emergem em seus textos de meados da década de 1930. Assim, acreditamos poder pensar o que está por trás destas mudanças e entendê-las. Tanto o Dasein quanto a abertura se transformarão radicalmente, se aprofundando e ganhando nuances cada vez mais complexas - como o ensaio A Origem da Obra de Arte o demonstra, posto que neste Heidegger articula, ainda, pela primeira vez, história, sagrado e acontecimento do mundo, dando uma ênfase cada vez maior na questão da retração/ velamento e em como mundo pode se dar a partir de uma abertura que já é, desde o início, compartilhada. Em definitivo, podemos dizer que tal revisão só se completa com o conceito de Ereignis ou acontecimento-apropriativo, na obra Beiträge zur Philosophie.

Com o conceito de acontecimento-apropriativo, Heidegger propõe de maneira nova a proposição antes presente em Ser e Tempo segundo a qual não se pode pensar nenhum comportamento do ser-aí sem a prévia abertura do mundo. Para ele, o que muda é "como a determinação precisa do caráter do mundo" se dá. O ser-aí passa a receber seu caráter próprio do Ereignis, é como ele reconquista uma relação própria com a sua possibilidade que acontece graças à superação dos “em-virtude-de" (worum-willen) que constituíam o mundo, na ótica da instrumentalidade, assim se apropriando da totalidade do mundo de forma sempre repentina, “de uma vez só". Por isso, nos Beiträge, Heidegger irá se utilizar da metáfora do salto (Spruch) para falar do acontecimento-apropriativo, referindo-se ao caráter súbito, ou mesmo repentino ${ }^{2}$ do evento: o acontecimento apropriativo como tendo uma dinâmica repentina, um movimento instantâneo de rearticulação da historicidade do ser, no qual essa se abre "de uma única vez" em totalidade. Deste modo, o acontecimento-apropriativo representa o "conceito final" dentro das considerações de Heidegger sobre como pode um mundo histórico se estabelecer em sua medida. $\mathrm{O}$ dar-se do ser como um mundo não depende mais, assim, do ser-aí para a sua determinação, e nem para a determinação do significado de cada ente que atravessa seu evento.

2 No sentido de que não é uma decisão da qual possamos nos aproximar através de um processo lógico formal ou através de processo gradual, muito pelo contrário. 
Antes, isso conduzirá a uma nova consideração da interpretação heideggeriana da história, cujos diferentes momentos podem assim ser - como um todo - compreendidos. O movimento historial do ocidente como história da metafísica seria, então, um todo perpassado por diferentes modos de configuração da abertura do ser (aquele âmbito "hermenêutico-compreensivo" pré-discursivo, subjacente a toda configuração histórica de mundo, antes mencionado), que já sempre se enviou - como diferentes "configurações contextuais" que dariam a cada época seu "tom característico" e marcariam profundamente toda possibilidade de compreensão do ente em cada momento histórico. Aliás, cada mundo histórico se refere a uma reconfiguração da totalidade, que marca assim, em cada época, como cada ente singular pode ser compreendido.

Foi no mundo grego que aconteceu pela primeira vez no Ocidente. O que a partir daí veio a se chamar "ser" foi posto em obra de modo paradigmático. $\mathrm{O}$ ente assim aberto na totalidade foi então transformado em ente no sentido do que foi criado por Deus. Isto aconteceu na Idade Média. Este ente, por seu turno, foi de novo transformado no início e no decurso dos tempos modernos. O ente tornou-se objeto calculável, suscetível de ser dominado e devassado. A cada vez irrompeu um mundo novo e essencial (HEIDEGGER, UK, 1977, p. 64-65).

Encerrando o presente texto, temos que, com isso, se evidencia que as conclusões de A Origem da obra de arte, acerca da historicidade fundamental de toda obra de arte, são um marco para o reposicionamento da questão do ser, pois representarão a ênfase na possibilidade de se pensar o acontecimento do ser já em sua abertura articulada como um mundo histórico. Posteriormente, a obra heideggeriana cada vez mais se direcionará não apenas para a perspectiva da historicidade inerente ao Dasein, como também procurará pensar o Dasein na perspectiva da tradição filosófica, pondo a tradição metafísica como determinante dos valores e significados do mundo ocidental ao longo de sua história e até hoje, em seu acabamento. 
CASANOVA, Marco Antonio. "Pensiero in transizione": Heidegger e l' "altro inizio” della filosofia. In: Giornale di metafisica. Genova: Tilgher, 2009, vol. 31, nº 1 , pp.43-70.

DUARTE, André. "Heidegger e a obra de arte como acontecimento historial-politico". In: Revista Artefilosofia, Ouro Preto, IFAC/UFOP, jul. 2008, n. 5.

DUBOIS, Christian. Heidegger: Introdução a uma leitura. Rio de Janeiro: Jorge Zahar editor, 2004.

DUQUE ESTRADA, Paulo César. "Sobre a obra de arte como acontecimento da verdade". In: O que nos faz pensar, n. ${ }^{\circ} 13$. Abril de 1999.

FIGAL, G. Heidegger zur Einführung. Hamburg: Junius, 1992.

HEIDEGGER, M. "Der Ursprung des Kunstwerkes". In: Holzwege, GA 5. Frankfurt am Main: Vittorio Klosterman, 1977.

HEIDEGGER, M. Beiträge zur Philosophie: vom Ereignis, GA 65. Frankfurt am Main: Vittorio Klostermann, 1994.

HEIDEGGER, M. Nietzsche I \& II. Frankfurt am Main: Vittorio Klostermann, 1985.

HEIDEGGER, M. Sein und Zeit. Tübingen: Max Niemeyer Verlang, 1976.

MARX, Werner. Heidegger und die Tradition. Hamburg: Felix Meiner Verlag, 1980.

NUNES, Benedito. Passagem para o poético: filosofia e poesia em Heidegger. São Paulo: Ática, 1986.

RICHARDSON, W. J. Heidegger: Through Phenomenology to thought. New York: The Hague, 1963.
SALLIS, John. Echoes after Heidegger. Bloomington and Indianapolis: Indiana University Press, 1990.

VATTIMO, Gianni. Introdução a Heidegger. Lisboa: Edições 70, 1989.

YOUNG, J. Heidegger's Philosophy of Art. Cambridge: Cambridge University Press, 2001. 